\title{
Root and Shoot Growth Periodicity of Green Ash, Scarlet Oak, Turkish Hazelnut, and Tree Lilac
}

\author{
J. Roger Harris,' Nina L. Bassuk, ${ }^{2}$ Richard W. Zobel ${ }^{3}$, and Thomas H. Whitlow ${ }^{4}$ \\ Urban Horticulture Institute, Cornell University, Ithaca, NY 14853
}

Additional index words. rhizotron, minirhizotron, phenology

\begin{abstract}
The objectives of this study were to determine root and shoot growth periodicity for established Fraxinus pennsylvanica Marsh. (green ash), Quercus coccinea Muenchh. (scarlet oak), Corylus colurna L. (Turkish hazelnut), and Syringa reticulata (Blume) Hara 'Ivory Silk' (tree lilac) trees and to evaluate three methods of root growth periodicity measurement. Two methods were evaluated using a rhizotron. One method measured the extension rate (RE) ofindividual roots, and the second method measured change in root length (RL) against an observation grid. A third method, using periodic counts of new roots present on minirhizotrons (MR), was also evaluated. RE showed the least variability among individual trees. Shoot growth began before or simultaneously with the beginning of root growth for all species with all root growth measurement methods. All species had concurrent shoot and root growth, and no distinct alternating growth patterns were evident when root growth was measured by RE. Alternating root and shoot growth was evident, however, when root growth was measured by $R L$ and MR. RE measured extension rate of larger diameter lateral roots, RL measured increase in root length of all diameter lateral roots and MR measured new root count of all sizes of lateral and vertical roots. Root growth periodicity patterns differed with the measurement method and the types of roots measured.
\end{abstract}

The relationships between root and shoot growth of trees have long been studied and debated (Reich et al.. 1980, Resa, 1878, Wieler, 1894). Differences among species in root and shoot growth patterns are often a result of evolved genetic responses to environmental stimuli (Liu et al., 1993). although much genotype $\times$ environment interaction may occur (Zobel, 1992). It has been suggested that as much as $30 \%$ of the entire plant genome is devoted to root growth and development (Zobel, 1975). Mathematical descriptions of root and shoot growth patterns are most often based on feedback between roots and shoots from resource limitation, which results in the maintenance of favorable root : shoot ratios (Borchert, 1973: Thornley, 1972). Feedback relationships may be mediated by limited water (Bevington and Castle, 1985), mineral nutrients (Mertins and Wright, 1978). carbohydrates (Dumbroff and Webb, 1978). or growth regulators (Goodwin et al., 1978) shared between roots and shoots. The supply of these rcsources is also strongly influenced by environmental factors.

There arc many reports ofopposing shoot and root growth patterns in trees. For example, alternating cycles of shoot and root growth were reported on Quercus alba and Q. marilandica by Reich et al. (1980) and on citrus by Bevington and Castle (1985). However, Cripps (1970) found that root and shoot growth were concurrent on apple trees, and Langlois et al. (1983) showed that no clear cyclic pattern existed between root and shoot growth for four of five conifers. Research on the relationships between root and shoot growth of trees presents conflicting results because species, sizes, and climates arc confounded among studies (Lyr and Hoffmann, 1967).

Shoot growth can be measured with relatively little difficulty since shoots are easily observed and readily accessible. However, the measurement of root growth poses a substantially more diffi-

Received for publication 24 June 1994. Accepled for publication 10 Od. 1994. The authors would like to express gratitude to Georese Schictel, Schictcl's Nursery Orchard Park, N.Y. for plant material used in this study. The cost ot publishing this paper was defrayed in part by the payment of page charges. Under postal regulations, this paper therefore must be hereby marked advertisement solely to indicate this fact.

'Former graduate rescarch assistant. Current address: Dept. of Horticulture, VPI \& SU, Blacksburg. VA 24061.

'Professor.

'Associate professor. Dept of Plant Breeding and Biometry, Cornell Univ. Ithaca NY 14853

${ }^{4}$ Assistant prolessor. cult challenge. Destructive sampling methods such as coring or excavations of root systems. are often used in root studies (Böhm, 1979). Although excavation of the root system is the only way to examine the entire root system of trees. it is very labor intensive. Soil cores may be used as subsamples, but they miss a high percentage of the total root mass. These methods also require a large number of replicates since each tree may be sampled only once. This results in an increased random error compared to measurements made periodically on the same tree (Böhm, 1979).

The observation of root growth against glass walls is an effective and nondestructive method forexamining seasonal root growth (Huck and Taylor, 1982). Similar to other sampling methods. however, only a portion of the root system may be observed, but the ability to make nondestructive multiple observations is an advantage. Root growth may be measured either by calculating the change in root length against the viewing panel over time with the line-intersect method (Newman, 1966) or by measuring the growth rate of individual roots (Hoffmann, 1966). To date, the best method for determining seasonal root growth for large-sized (landscapesized) trees is to use rhizotrons. An alternative method is to observe roots growing against glass or acrylic tubes with the aid of fiber optics or a miniature movie camera (minirhizotron) (Taylor, 1987). Rhizotron facilities can be quite elaborate and expensive to build (Huck and Taylor, 1982). Minirhizotrons. however, are relatively inexpensive and portable. Access tubes can be installed directly in agricultural or natural settings.

A fundamental understanding of root and shoot growth patterns is lacking for established landscape-sized trees growing in the northeastern United States. This is the first report describing these patterns. The objective of this study was 2-fold: 1) to determine the best method for nondestructively measuring root growth periodicity and 2) to determine the relationships between periodic shoot and root growth of green ash, scarlet oak, Turkish hazelnut, and tree lilac.

\section{Materials and Methods}

Rhizotron construction. Two trenches, each measuring $1 \mathrm{~m}$ wide $\times 1 \mathrm{~m}$ deep $\times 8 \mathrm{~m}$ long, were excavated near the campus of Cornell Univ., Ithaca, N.Y., in early Spring 1991. Clear polycarbonate (Lexan) plates $6.35 \mathrm{~mm}$ thick $\times 61 \mathrm{~cm}$ wide were fastened 
to wooden frames and placed so that the smooth Lexan side was against the entire length of the two long carthen walls of each trench. The framed Lexan plates were held in place by a series of posts and beams. Each trench was fitted with drains, and the floor was covered with $10 \mathrm{~cm}$ of gravel. Each trench was fitted with a three-part. removable, 1-cm-thick plywood cover. Soil type was Williamson silty clay loam ( $\mathrm{pH}$ 6.2). Copper-constantan thermocouples connected to a datalogger (CR 21; Campbell Scientific, Logan, Utah) were placed through the Lexan plate of one rhizotron $5 \mathrm{~mm}$ and $25 \mathrm{~cm}$ into the soil profile at depths of 30 and $45 \mathrm{~cm}$ to assess the effect of the rhizotron on soil temperature. Soil temperature at $20 \mathrm{~cm}$ was monitored continuously by a weather station $\approx 500 \mathrm{~m}$ from the test sight. Foam insulation $(5 \mathrm{~cm}$ thick) was placed against the Lexan plates beginning in early November and removed in early April.

Plant material. Fraxinus pennsylvania. (green ash), Q. coccinea. (scarlet oak), Corylus colurna. (Turkish hazelnut), and Syringa reticulata 'Ivory Silk' (tree lilac) were chosen because they varied in transplantability and shoot growth characteristics. It was hypothesized that root growth of easy-to-transplant species has a different pattern than difficult-to-transplant species. Green ash and tree lilac transplant with relative ease, while scarlet oak and Turkish hazelnut transplant with relative difficulty (Flemmer, 1990). Green ash and scarlet oak shoots usually make more than one seasonal growth flush (recurrent growth), whereas Turkish hazelnut and tree lilac shoots usually make only one growth flush during the growing season (fixed growth). This choice of species results in fourdistinct root growth and shoot growth combinations.

1) An easy-to-transplant species with recurrent growth (green ash)

2) An easy-to-transplant species with fixed growth (tree lilac).

3) A difficult-to-transplant species with recurrent growth (scarlet oak).

4) A difficult-to-transplant species with fixed growth (Turkish hazelnut).

These combinations create adesign under which the hypothesis that there is no distinct trade off between root and shoot growth for landscape-sized trees can be tested.

All trees were planted bare-root immediately adjacent to the sides of the rhizotrons in May 1991 in a randomized completeblock design (one replicate of each species randomly planted along each of the four sides). The distances between all trees was $2 \mathrm{~m}$. Growth measurements began in Spring, 1992. Height and trunk diameter $(10 \mathrm{~cm}$ above soil) were measured for each species just before budbreak in 1992. Mean height $(\mathrm{m})$ and caliper $(\mathrm{cm})$ (SE mean in parentheses) were 2.08(0.44) and 3.1(0.2) for scarlet oak. 3.32(0.18) and 5.1(0.1) for green ash. 2.25(0.03) and 3.1(0.02) for Turkish hazelnut, and 2.48(0.09) and 2.8(0.1) for tree lilac. One scarlet oak was excluded from growth measurements because of defoliation by gypsy moths.

Shootgrowth measurements. Five shoots with the largest diameters were selected on each replicate tree and marked for shootlength measurements. Periodic increase in shoot length [shoot extension $\left.\left(\Delta_{\mathrm{SE}}\right)\right]$ for each replicate was determined by subtracting

$\mathrm{SE}=\frac{\Delta_{\mathrm{SE}}}{\mathrm{T}_{\mathrm{SE}}} \times 100$

the previous length of each of the five shoots from the current length and calculating the mean of the five measurements. At the end of the growing season, the rate of increase in shoot length for each measurement day (SE) was calculated for each replicate by where $\Delta_{\mathrm{SE}}=$ increase in extension between measurements, $\mathrm{T}_{\mathrm{SE}}=$ total shoot extension for the season, and $\mathrm{t}=$ time (days) between measurements. Means of all replicates for each species and the standard errors of the means were then calculated.

Rhizotron root growth measurements. Root measurements in the rhizotron were generally made every 10 to 15 days during the growing season in the early morning to minimize irradiance on the rhizotron walls. Seasonal root growth against the rhizotron walls was measured in two ways. Change in root length was measured using the line intersect method of Newman (1966) as modified by Tennant (1975). Measurements were taken on a $50 \times 50-\mathrm{cm}$ grid with $5 \times 5-\mathrm{cm}$ increments drawn directly on the Lexan plate. The grid was centered on the trunk of each tree. All visible roots on the grid were used in the measurements. Root length was represented as the calculated root length present against the observation grid. Periodic change in root length $\left(\Delta_{\mathrm{RL}}\right)$ for each replicate was determined by subtracting the previous root length from the current length. At the end of the growing season, the rate of increase in root length for each replicate (RL) was calculated by

$\mathrm{RL}=\frac{\Delta_{\mathrm{RL}}}{\mathrm{T}_{\mathrm{RL}}} \times 100$

where $A_{R L}=$ increase in root length between measurements, $T_{R L}=$ total increase in root length for the season and $t=$ time (days) between measurements. Means of all replicates for each species and the standard errors of the means were then calculated.

Root extension was also measured by marking the most vigorously growing roots with colored marking pens on the Lexan plates. Measurements were made on all Lexan plates where root growth could be observed. Incremental growth for each marked root was then measured. Root extension for each replicate was the single maximum extension $\left(\Delta_{\mathrm{RE}}\right)$ measured. At the end of the growing season, the rate of increase in root extension for each measurement day (RE) was calculated for each replicate by

$\mathrm{RE}=\frac{\Delta_{\mathrm{RE}}}{\mathrm{T}_{\mathrm{RE}}} \times 100$

where $\Delta_{\mathrm{RE}}=$ increase in maximum root extension between measurements. $T_{R E}=$ total increase in maximum root extension for the season and $\mathrm{t}=$ time (days) between measurements. Means of all replicates for each species and the standard errors of the means were then calculated.

Minirhizotron root growth measurements. One acrylic access tube per tree was placed $60 \mathrm{~cm}$ from the trunk and equidistant from the rhizotron wall as the trunk. Tubes were installed soon after transplanting at about a $45^{\circ}$ angle with the in-ground portion toward the tree. The tubes were $107 \mathrm{~cm}$ long $\times 5 \mathrm{~cm}$ in diameter. Thirty centimeters of the length was above ground and painted black to exclude light and reduce condensation. Exposed ends were capped to prevent rain water contamination.

The minirhizotron was equipped with a video camera (Upchurch and Richic, 1983) with a 17-mm-wide field of view, and the video camera was connected to a video recorder. The camera was periodically slowly lowered down the access tubes, and the results were recorded on video tape. Constant camera position for each periodic measurement was assured by a mark on each access tube. Root growth was measured by making counts of new (white) roots present along the entire length of the access tube at each measurement. 
Incremental root count $\left(\Delta_{R}\right)$ was calculated from total root count at each measurement for tree lilac since roots did not darken with age, and the determination of new root count was difficult. At the end of the growing season, the rate of increase in new roots present on the minirhizotron for each replicate (MR) was calculated by

$\mathrm{MR}=\frac{\Delta_{\mathrm{R}}}{\mathrm{T}_{\mathrm{R}}} \times 100$

where $\Delta_{R}=$ number of new roots counted, $T_{R}=$ total number of new roots counted over the entire growing season, and $t=$ time (days) between measurements. Means of all replicates for each species and the standard errors of the means were then calculated.

A comparison between root length density $\left(\mathrm{cm} \cdot \mathrm{cm}^{-2}\right)$ on the rhizotron and the minirhizotron was made on all replicates of tree lilac on 21 July 1993. The video camera of the minirhizotron was lowered at $2-\mathrm{cm}$ intervals for the entire length of the access tubes, and root length per square centimeter of observation panel was computed using the line intersect method described above. The viewing monitor, assuming a $1.5 \times 1.5-\mathrm{cm}$ field of view, was used as the grid unit. After checking normality. the means were computed, and the statistical difference between the means was assessed by a $t$ test.

Values of SE, RLD, RE, and MR all have units ofpercent per day. This allows for easier comparisons between species and among methods than if different scales were used for each species and method. Each change of $1 \%$ daily growth rate for tree lilac, for example, represents a change of $-26.2 \mathrm{~cm}, 0.9 \mathrm{~cm}$. and 1.4 roots for RLD, RE, and MR, respectively. The roots of tree lilac would therefore be adding $26.6 \mathrm{~cm}$ of length a day to the observation grid if RL was at $1 \%$ and $78.6 \mathrm{~cm}$ if RL was at $3 \%$. Each method was separately subjected to analysis of variance (species in a randomized complete-block design), and equality of variance between methods was tested using Bartlett's test (Snedecor and Cochran, 1988).

\section{Results and Discussion}

Root growth periodicity. Root growth (RL) began in middle to late May for all species (Fig. 1). Rate of root length increase was bimodal for scarlet oak and green ash, with peak growth occurring in early summer and early fall. Similar patterns have been observed on apples in England (Rogers, 1935) and pine in the southern United States (Reed, 1939). This agrees with the early theory that most tree species have bimodal root growth patterns with peaks in early sutnmer and early fall (Engler, 1903). In the present study, however, root growth of Turkish hazelnut trees occurred mainly in June and July and did not show the resurgence of growth rate in the fall that was evident in scarlet oak and green ash. Similar differences in root growth patterns among tree species were reported by Hoffmann (1966). Growth of tree lilac roots was more evenly distributed over the growing season. and growth began at a somewhat slower rate in the spring than for the other species.

Bimodal root growth patterns were less evident on scarlet oak and green ash when assessed by the RE method (Fig. 2). Most root extension took place in June and July, and a small increase in activity was present in October. In contrast to scarlet oak and green ash. Turkish hazelnut and tree lilac had more-uniform seasonal root growth.

Measurements of root growth assessed using the minirhizotron measurements revealed results different from the rhizotron study (Fig. 3). Root growth patterns determined by the MR method for scarlet oak and green ash were intermediate from the RL and RE methods (Figs. 1 and 2). All methods indicated major root growth

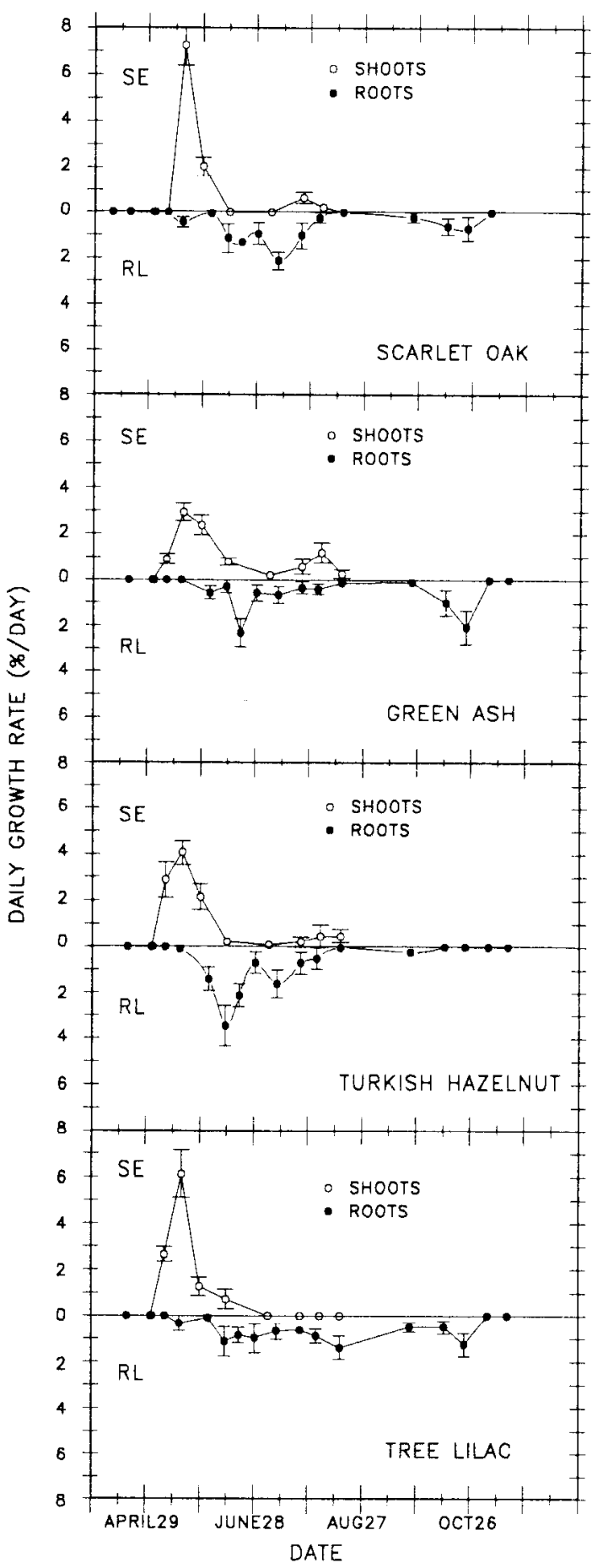

Fig. 1. Daily shoot growth rate (SE) and root growth rate calculated by increase in root length against observation grids on a rhizotron (RL) for scarlet oak, preen ash, Turkish hazelnut, and tree lilac. Error bars represent the standard error of the means: $n=4$.

in early to middle summer, with a much smaller increase in growth activity in the fall. However, the amplitudes of the root growth curves varied most when assessed by the root length method. Amplitudes were intermediate when assessed by the minirhizotron method (Fig. 3). and they were least when assessed by the root extension method (Fig. 2). MR and RL indicated major activity in early summer for Turkish hazelnut, but contrary to results obtained from RL measures, MR indicated a bimodal root growth pattern for all species. RE indicated a more uniform seasonal pattern than either RL or MR. MR indicated less early and more late season root 


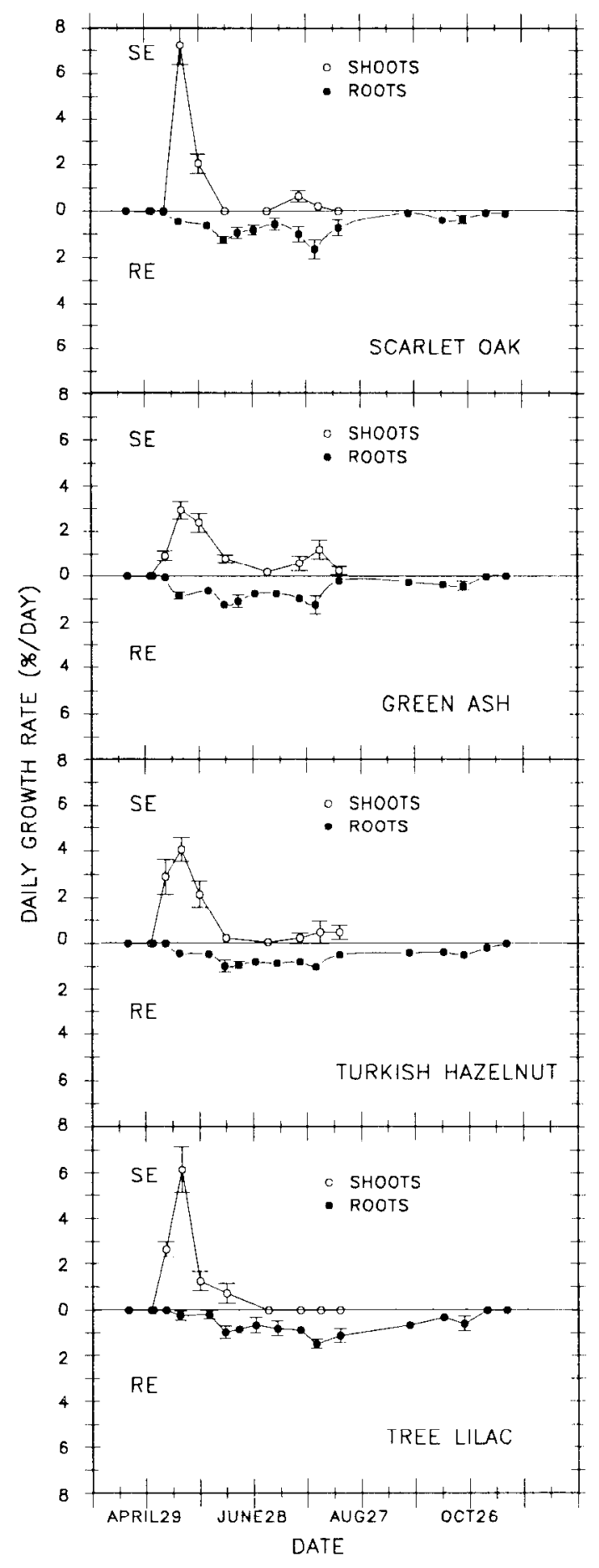

Daily shoot and root growth rates calculated by change in extcnsion (SI and for scarlet oak, green ash. Turkish hazelnut, and tree lilac. Error hars esent the standard crrors of the meams; $n=4$

growth than the other methods.

Root growth patterns of tree lilac measured by RL and RE were similar. MR, however, indicated a growth peak in early September. A minor fall surge in growth was also indicated by RE and RL. but activity was in late October, not early September.

The root extension method (RE) may he less sensitive than the root length method (RL) to shoot effects because only the larger. most rapidly growing roots are measured with RE. whereas all sizes of roots are counted with RL. Root diameters for RE ranged from 1.0 to $2.0 \mathrm{~mm}$, whereas RL and MR root diameters ranged from 0.2 to $2.0 \mathrm{~mm}$. RL and RE methods measured only lateral

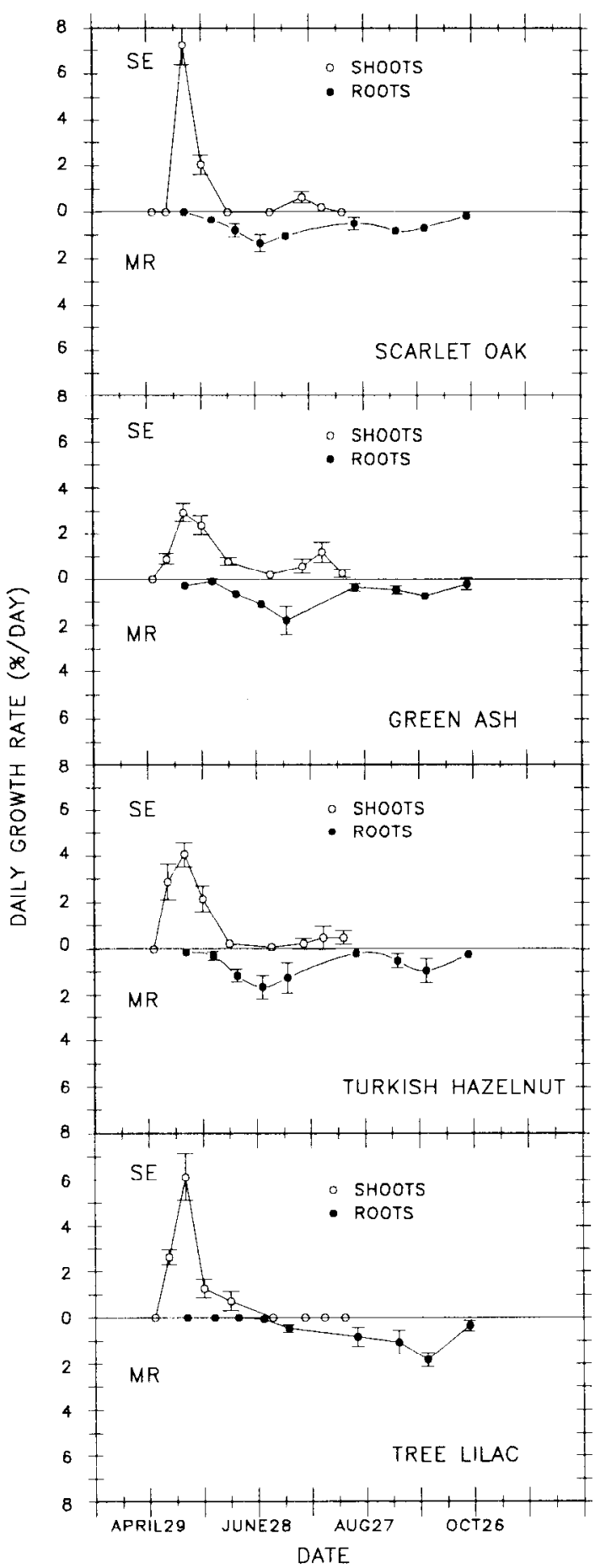

Fig. 3. Daily shoot grow th rate (SE) and root growth rate calculated by root coun on minirhizotrons (MR) for scarlet oak. green ash. Turkish hazelnut, and tre lilac. Error bars represent the standard errors of the means: $n=4$.

growing roots, since these were the roots intercepted by the rhizotron wall. MR, however, measured all sizes of roots, and the 45 angle of the access tubes assures the interception ofvertical and horizontal roots. MR, therefore is a composite sample of all types of newly formed roots. MR. however, has the disadvantage of having a much smaller sampling area than the RL or RE methods.

Determination of RL presented special problems not emphasized in previous descriptions of rhizotron methodology. Rainfall in 1992 was $15 \%$ above normal, with much precipitation occurring during the growing season. Although this kept soil moisture levels high, which did not limit growth. water moving through the profile 
occasionally caused silt and clay particles to accumulate against the Lexan plates, and viewing the roots was more difficult. This was exacerbated by the natural suberization and subsequent darkening of the older roots of scarlet oak and Turkish hazelnut (Kramer and Kozlowski, 1979). Green ash and tree lilac roots darkened very little with age, suggesting that suberization was minimal.

There is no established protocol for the number of minirhizotron tubes required to sample periodic root growth of landscape sized trees adequately. This study, which measured periodic changes in the number of roots present, utilized one tube per tree and four trees per species. Somewhat different results may have been obtained if more tubes per tree or replicates were used. However, root length density data $\left(\mathrm{cm} \cdot \mathrm{cm}^{-2}\right)$ were determined to be statistically similar between the rhizotron and the minirhizotron when observed on tree lilac on 21 July 1993. Mean densities (SE mean in parentheses) were calculated to be $3.40(0.97) \mathrm{cm} \cdot \mathrm{cm}^{-2}$ for the rhizotron and $3.51(0.81) \mathrm{cm} \cdot \mathrm{cm}^{-2}$ for the minirhizotron. Comparisons were not made for other species. Data from the minirhizotron, therefore, compared very favorably with the data taken from the rhizotron for tree lilac, even though a much smaller field of view was used. The portability and data recording aspects of the minirhizotron method offer much potential for future research on tree root growth.

The RL method was the most difficult method to implement because of the viewing difficulties discussed above. This was likely a function of the soil type and may not occur in soils containing less silt. MR was not as subject to increased viewing difficulty as RL because of the magnification and lighting used. RE, however, had the advantage of a larger field of view than RL or MR, since all Lexan plates were sampled. This may have been a factor in the lower variability of RE. Mean square error comparisons revealed a lower value for RE compared to RL or MR with Bartlett's test $(P<0.001)$.

Soil temperature. Root growth began on all species at soil temperatures between 12 to $15 \mathrm{C}$ in the spring and ended at -6 to $8 \mathrm{C}$ in the fall (measured $20 \mathrm{~cm}$ deep). No significant differences were measured between soil temperatures just adjacent to the Lexan wall and temperatures $2.5 \mathrm{~cm}$ into the soil profile at either depth or at any time of the year (data not shown). The greatest difference was $1 \mathrm{C}$.

Shoot growth periodicity. Scarlet oak began shoot growth slightly later than the other species (Figs. 1-3). Initial SE was rapid and brief. As predicted, shoot growth was recurrent, and a second shorter flush of growth followed after a short period of bud rest. Green ash also exhibited recurrent shoot growth. Initial shoot extension, however, was more sustained, and the second flush of growth was somewhat greater than that of scarlet oak. There were no apparent opposing growth patterns between SE and RE (Fig. 2) for scarlet oak or green ash. In fact, shoot and root extension rate increased simultaneously. Turkish hazelnut and tree lilac showed rapid early shoot extension. In contrast to tree lilac, Turkish hazelnut had a slight recurrence of shoot growth in midsummer. This was a result of a few shoots in the lower canopy. Besides the few late breaking shoots of Turkish hazelnut, seasonal SE and RE patterns of Turkish hazelnut and tree lilac were similar. As in scarlet oak and green ash, no trade-off was evident between shoot and root growth, although the largest root growth of tree lilac occurred after the cessation of shoot growth.

Shoot growth commenced before root growth for all species except scarlet oak (Figs. I-3). Scarlet oak began shoot growth later than the other species, simultaneously with root growth. The absence of any detectable root growth before spring budbreak was unexpected and contrary to most reports for trees in general.
Dumbroff and Webb (1978) reported that root growth occurred before budbreak on sugar maple (Acer saccharum Marsh.). Sugar maple, however, can apparently grow roots in very cold soils (Morrow, 1950). Glenn and Welker (1993) reported that root growth occurred before shoot growth for peach in the warmer soils of West Virginia, and Reich et al. (1980) reported similar data for four species of oak in the warmer soils of Missouri. The different results in our report therefore may be a function of the species tested and the cold spring soils found in upstate New York.

In contrast to the relationship between SE and RE (Fig. 2), an alternating growth pattern between shoot and root growth was evident for SE and MR (Fig. 3). The larger, lateral roots measured by $\mathrm{RE}$ are apparently not substantially influenced by shoot growth patterns, but the smaller diameter roots measured by MR are. This alternating pattern is also suggested when SE is compared to RL (Fig. I). The question of whether landscape-sized trees grow with alternating shoot and root growth patterns, therefore, depends on the types of roots measured and the method used for measurement. Measurements of root growth in this study were direct and indirect measurements of root elongation. Different results may have been obtained if root diameter or dry weight increases had been measured. Research is needed on the physiological function of different types of roots before the consequences of their growth patterns can be accurately assessed.

\section{Literature Cited}

Bevington, K.B. and W.S. Castle. 1985. Annual root growth pattern of young citrus trees in relation to shoot growth, soil temperature, and soil water content. J. Amer. Soc. Hort. Sci. 1 10:840-845.

Böhm. W. 1979. Methods of studying root systems. Ecological studies. Springer-Verlag, Berlin.

Borchert, R. 1973. Simulation of rhythmic tree growth under constant conditions. Physiol. Plant. 29: 173-180.

Cripps, J.E.L. 1970. A seasonal pattern of apple root growth in western Australia. J. Hort. Sci. 45:153-161.

Dumbroff, E.B. and D.P. Webb. 1978. Physiological characteristics of sugar maple and implications for successful planting. For. Chron. 54:92-95.

Engler, A. 1903. Untersuchungen über das Wurzel wachstum der Holzarten. Mitt. Schweiz. Centralanstalt forstl. Versuchswes 7:247-272.

Flemmer, III., W. 1990. Wholesalecatalog. Princeton Nurseries, Princeton, N.J.

Glenn, D.M. and W.V. Welker. 1993. Root development patterns in field grown peach trees. J. Amer. Soc. Hort. Sci. 118:362-365.

Goodwin, P., B. Gollnow, and D. Letham. 1978. Phytohormones and growth correlations. In: D. Leatham, P. Goodman, and T. Higgins (eds.). Phytohormones and related compounds-A comprehensive treatise. Biomedical Press, Amsterdam.

Hoffmann, G. 1966. Verlauf der Tiefendurchwurzelung und Feinwurzelbildung bei einigen Baumarten. Arch. Forstwes. 15:825826.

Huck, M.G.. and H.M. Taylor. 1982. The rhizotron as a tool for root research. Adv. Agron. 35:1-35.

Kramer, P.J. and T.T. Kozlowski. 1979. Physiology of woody plants. Academic Press. Orlando.

Langlois, C.G., L. Godbout. and J.A. Fortin. 1983. Seasonal variation of growth and development of the roots of five second year conifer species in the nursery. Plant and Soil 71:55-62.

Liu, M., R. Li, and M. Liu. 1993. Adaptive responses of roots and root systems to seasonal changes. Environ. Expt. Bot. 33:175-188.

Lyr, H, and G. Hoffmann. 1967. Growth rates and growth periodicity of tree roots. Intl. Rev. For. Res. p. 181-236.

Mertins, M. and R. Wright. 1978. Root and shoot relationships of two cultivars of Japanese holly. J. Amer. Soc. Hort. Sci. 103:722-724.

Morrow, R.R. 1950. Periodicity and growth of sugar maple surface layer roots. J. For. 48:875-881. 
Newman. E.I. 1966. A method of estimating the total length of root in a sample. J. Applied. Ecol. 3:139-145.

Reed. J. 1939. Root and shoot growth of short leaf and loblolly pines in relation to certain environmental conditions. Bul. Duke School For. 4:1-52.

Reich, P.B., R.O. Teskey, P.S. Johnson, and T.M. Hinckley. 1980 Periodic root and shoot growth in oak. For. Sci. 26:590-598.

Resa, F. 1878. The phenology of root formation especially of woody plants. Forstl. RI. 15:321-331.

Rogers, W. 1935. Root studies. VI. Apple roots under irrigated conditions with notes on use of a soil moisture meter. J. Pomol. Hort. Sci. 17:67-84.

Snedecor, G.W. and W.G. Cochran. 1989. Statistical methods. 8th ed. Iowa State University press. p. 251-252.

Taylor. H.M. 1987. Minirhizotron observation tubes: Methods and applications for measuring rhizosphere dynamics. Amer. Soc. Agron., Madi- son, Wis.

Tennant, D. 1975. A test of a modified line intersect method of estimating root length. J. Ecol. 63:955.

Thornley, J. 1972. A model to describe the partitioning of photosynthate during vegetative plant growth. Ann. Bot. 36:419-430.

Upchurch, D.R. and J.T. Ritchie. 1983. Root observations using a video recording system in mini-rhizotrons. Agron. J. 75:1009-1015.

Wieler, A. 1894. Periodicity in the root formation of plants. Forstwiss Cbl. 16:333-349.

Zobel, R.W. 1975. The genetics of root development., p. 261-275. In: J. Torrey and D. Clarkson (eds.). The development and function of roots. Academic Press, London.

Zobel, R.W. 1992. Soil environment constraints to root growth. Adv. Soil Sci. 19:27-51. 